\title{
Teaching with Cultural Heritage Materials During the Pandemic
}

Liam Sweeney

Kurtis Tanaka 


\section{ITHAKA S+R}

Ithaka $\mathrm{S}+\mathrm{R}$ provides research and strategic guidance to help the academic and cultural communities serve the public good and navigate economic, demographic, and technological change. Ithaka $\mathrm{S}+\mathrm{R}$ is part of ITHAKA, a not-for-profit with a mission to improve access to knowledge and education for people around the world. We believe education is key to the wellbeing of individuals and society, and we work to make it more effective and affordable.

Copyright 2022 ITHAKA. This work is licensed under a Creative Commons Attribution 4.0 International License. To view a copy of the license, please see https://creativecommons.org/licenses/by/4.0/.

ITHAKA is interested in disseminating this brief as widely as possible. Please contact us with any questions about using the report: research@ithaka.org. 


\section{Table of Contents}

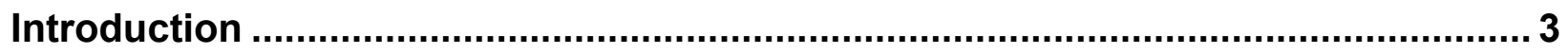

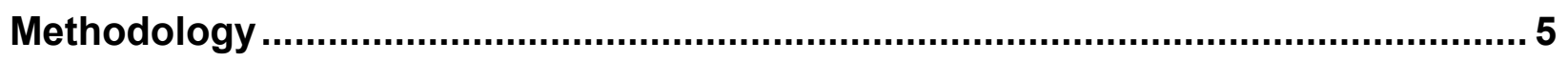

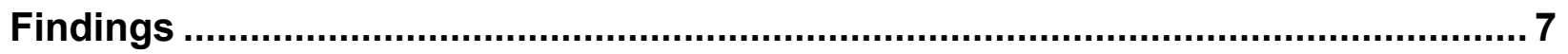

Hybridizing the Encounter with Cultural Heritage Materials ................................... 8

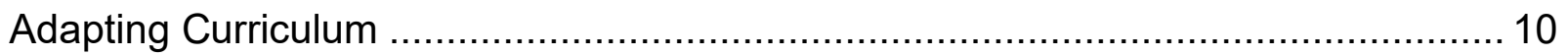

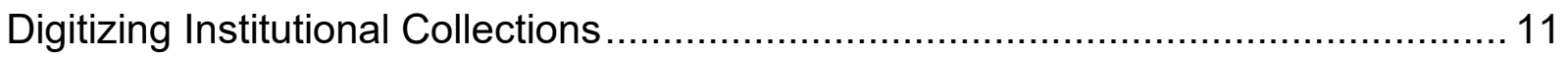

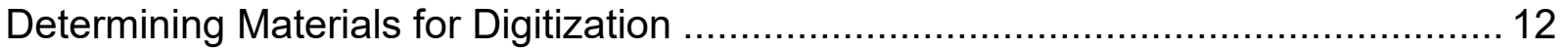

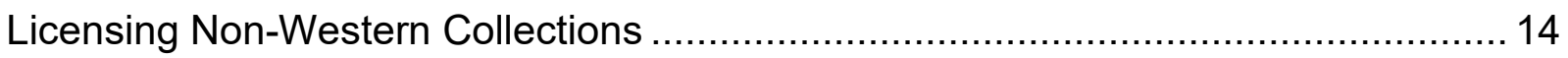

Student Fluency with Collections and Cultural Spaces ......................................... 15

Discovery and Commercial Search Engines ...................................................... 17

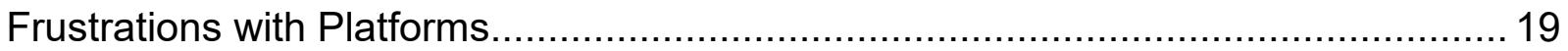

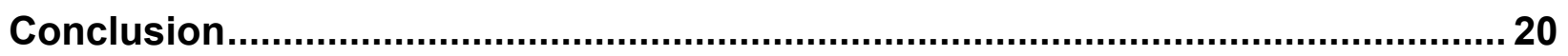




\section{Introduction}

Cultural heritage materials can offer rewarding learning opportunities and impactful experiences for students across a variety of disciplines, especially in the humanities and social sciences. ${ }^{1}$ These learning opportunities create important historical and/or cultural context within a discipline, ${ }^{2}$ allowing students to deepen their engagement with a discipline, or see themselves, perhaps for the first time, as a scholar. 3

However, the COVID-19 pandemic, and the attendant move to online instruction at many colleges and universities, disrupted pedagogical practices and the ways that instructors incorporate cultural heritage materials into their courses. In this study, funded by The Andrew W. Mellon Foundation, we explore how cultural organizations and academic libraries responded to the pandemic, the challenges instructors faced in adapting their courses, and what steps were taken to alleviate educational inequity. This report shares the perspectives of instructors on their changing relationship to collections and evolving teaching practices, as well as their observations about how their institution's response to the pandemic had an impact on teaching with cultural heritage materials.

The higher education sector has, like many sectors of our economy and society, found remarkable ways to evolve and adapt during the COVID-19 pandemic in order to continue providing, in some form or other, formative educational experiences and valuable learning outcomes sought by both students and instructors. Instructors who teach with cultural heritage materials in particular have faced challenges when adapting to remote learning, since their instruction is often centered around in-person, live engagements with physical materials. For many instructors, the shift to remote learning revealed just how central teaching with physical collections was in their pedagogy, highlighting the importance of students' experiences with cultural heritage materials and the value of place-based learning. 4 At the same time, many instructors found inventive ways to incorporate digital cultural heritage materials into their curriculum or found other ways of adapting their courses to support primary source literacy and learning.

This study focuses on pedagogical adaptations during the pandemic. These changes have occurred within a larger social and public health context, which must be acknowledged. The

\footnotetext{
${ }^{1}$ We use the term "cultural heritage" rather than "primary sources" to be inclusive of museum collections. For our purposes, cultural heritage materials means primary source materials that have been selected for preservation and display, and which represent or reflect the human species' social or environmental relationship to a place, a population, concept, society, or aesthetic. These cultural heritage materials can be tangible or intangible, but for our purposes they will be represented through physical collections, which can be accessed remotely.

${ }^{2}$ Mary Catherine Kinniburgh, "The Space between Researcher, Object, Institution: Building Collaborative Knowledge with Primary Sources," The Journal of Interactive Technology and Pedagogy, 7 January 2019, https://jitp.commons.gc.cuny.edu/the-spacebetween-researcher-object-institution-building-collaborative-knowledge-with-primary-sources/.

${ }^{3}$ Elizabeth Yakel and Deborah Torres, "Al: Archival Intelligence and User Expertise," The American Archivist 66, no. 1 (2003): $51-$ 78, https://doi.org/10.17723/aarc.66.1.q022h85pn51n5800.

${ }^{4}$ Carrie Lynn Schwier and Carey Rebecca Beam, "Place-based Instruction in Archives: Our Pedagogical Roots," Comma: International Journal on Archives 2018, nos 1-2 (2018), https://doi.org/10.3828/comma.2018.18; David Sobel, "Place-based Education: Connecting Classroom and Community," Nature and Listening 4, no. 1 (2004): 1-7.
} 
COVID-19 pandemic has proven to be among the deadliest, most tragic, and transformative social and public health catastrophes of modern times. Despite the seeming universality of this pandemic, its effects have not impacted all students evenly. According to the Center for Disease Control (CDC), death rates have been substantially higher for Black (2.0x), Hispanic (2.3x) and American Indian or Alaska Natives (2.4x) populations, as compared to the white, non-Hispanic US population. 5 Research from the Pew Research Center shows that job losses have disproportionately impacted Hispanic women, immigrants, young adults and those with less education. ${ }^{6}$ A recent survey by The Hope Center of nearly 40,000 undergraduates from 54 colleges found that 60 percent experienced basic needs insecurity, including food, housing, childcare, and mental health resources. ${ }^{7}$ Basic needs insecurities were 19 percent more likely to be experienced by Black students than white students. In many cases, as students were instructed to conduct their coursework from home, institutions did not take into consideration the fact that many students rely on in-person university resources for productive learning. Instructors confirmed during interviews that many of their students struggled to balance their home, work and student lives. In some cases, students did not have adequate private space at home, or consistent internet access, while in others, they would log into classes on zoom from a jobsite, such as an Amazon warehouse, or a fast-food restaurant. Thus, while this project was interested in one specific element of pedagogy, it is critical that we remember the wider context in which these adaptations occurred as we seek to assess and understand them. ${ }^{8}$

While the pandemic challenged our ability to interact safely in person, the racial justice protests in the summer of 2020 as a response to police brutality against Black people have also had a significant impact on many institutions, including higher education. These impacts were evident in Ithaka S+R's interviews with instructors. Many cultural and education centers have issued statements condemning police violence and expressing solidarity with the Black Lives Matter movement and more broadly with victims of police brutality and systemic racism. In some cases, this has resulted in an effort for institutions to look inward and identify inequities or biases in their own organizations. Such concerns have, in some cases, become interwoven with student and instructors' efforts to adapt teaching and learning during the pandemic, and, therefore, we have included relevant observations from instructors on these issues as they arose in our interviews.

\footnotetext{
${ }^{5}$ As of publication, there have been over 860,000 deaths from COVID-19 in the United States according to the Center for Disease Control: https://covid.cdc.gov/covid-data-tracker/\#trends dailydeaths.

${ }^{6}$ Rakesh Kochhar, "Hispanic Women, Immigrants, Young Adults, Those with Less Education Hit Hardest BY COVID-19 Job Losses," Pew Research Center, 26 August 2020, https://www.pewresearch.org/fact-tank/2020/06/09/hispanic-women-immigrantsyoung-adults-those-with-less-education-hit-hardest-by-covid-19-job-losses/.

${ }^{7}$ Sara Goldrick-Rab, Venessa Coca, Gregory Kienzl, Carrie R. Welton, Sonja Dahl, and Sarah Magnelia, "\#REALCOLLEGE During the Pandemic," The Hope Center, June 2020, https://hope4college.com/wpcontent/uploads/2020/06/Hopecenter RealCollegeDuringthePandemic.pdf.

${ }^{8}$ For more information on how students have experienced the pandemic and the challenges they have faced see: Christy McDaniel, Catherine Suffern, Jenna Joo, and Rayane Alamuddin, "Student and Faculty Experiences with Emergency Remote Learning in Spring 2020," Ithaka S+R, 22 October 2020, https://doi.org/10.18665/sr.314276.
} 
This report captures the perspectives of instructors who were directly impacted by the shift to remote learning in one common way: they were no longer able to provide in-person learning opportunities with cultural heritage materials for their students. Instead, they adapted their curriculum in a variety of ways, revealing the challenges and opportunities of remote learning and digital cultural heritage tools in the conditions of a pandemic. 9 Because the pandemic has affected instructors, students, and institutions unevenly, it is incumbent on our educational and cultural institutions to find ways to continue their work through this disaster with a focus on equity, and to learn from these experiences in order to evolve, and to be more prepared for future disruptions. Therefore, we hope this report is useful to workers and leaders of galleries, libraries, archives and museums in colleges and universities, as well as to higher education administrators, campus information technology professionals, learning management system providers, digital cultural heritage platforms, and instructors.

\section{Methodology}

This research project employed a collaborative methodology, in which Ithaka $\mathrm{S}+\mathrm{R}$ researchers relied on library and museum staff to identify interview subjects. This approach enabled us to engage with practitioners who work in museums, archives, and special collections, while also allowing us to gather the perspective of instructors at a larger scale. To gather evidence from instructors, Ithaka S+R first developed a cohort of seven colleges and universities that would identify instructors who teach with cultural heritage materials to participate in the project. In building this cohort, we sought institutions that serve high proportions of first-generation students and minoritized students, and which had rich holdings of cultural heritage materials either in their archives and special collections, or in campus museums. Through outreach to either the library or museum, the following institutions joined the project:

- California State University, Northridge

- City University of New York

- Spelman College

- University of Hawaii

- University of Michigan

- University of Missouri

- University of Texas, San Antonio

Each institution identified strategic partners, typically one or two liaisons from the museum or library, who helped us navigate the institution's IRB and identify five instructors to interview. When developing our interview cohort, we focused on capturing, with the help of the local knowledge provided by the strategic partners, a variety of instructor experiences ranging from those who worked closely with the museum or library during the pandemic to those whose engagement had fallen off during the pandemic, or those who were known to use cultural

${ }^{9}$ We use the term instructors instead of faculty to be inclusive of lecturers, adjunct teaching staff, and other university staff who teach. 
heritage materials but did not typically do so through the library or museum. We also focused on representing a variety of disciplines in the project, including:

- African Diaspora Studies

- American Culture

- American Studies

- Anthropology

- Art and Visual Culture

- Chicanx Studies

- Communications

- Earth and Environmental Sciences

- English

- Gender and Women's Studies

- Hawaiian Language

- History

- Queer Studies

- Sociology

- Theater

Over the course of 2021, Ithaka S+R interviewed 35 instructors, following a semi-structured interview guide. These interviews, which lasted roughly 45 minutes to an hour, were recorded and transcribed by a third party. Transcripts were analyzed using the qualitative software program NVIVO. An interpretive research framework was employed to organize the evidence and develop findings. ${ }^{10}$

This project was guided by our advisory committee. Formed at the outset of the project, the advisory committee provided essential subject matter expertise, as well as a critical lens to couch evidence-based findings, which proved invaluable in the development of this report:

- Kim Christen, Director of the Digital Technology and Culture Program and the Director of the Center for Digital Scholarship and Curation, Washington State University

- Lareese Hall, Director of Colby Libraries, Colby College

- Petrina Jackson, Director Special Collections Research Center, Syracuse University Libraries

- Sharon Leon, Associate Professor of History and Digital Humanities, Michigan State University

- Anne McGrail, Faculty, Lane Community College

At the end of each findings section, we offer recommendations for specific audiences. While various audiences may be interested in each section for different reasons, our findings are

${ }^{10}$ Peregrine Schwartz-Shea and Dvora Yanow, Interpretive Research Design: Concepts and Processes, Routledge, 2013. 
oriented toward four main audiences: administration and staff of collecting organizations, higher education instructors, university administration, and leaders of digital collections platforms. These recommendations are derived from the evidence gathered and may not be relevant to all institutions. Recommendations do not assume uniform strategy and workflows across institutions.

While this report does focus on the ways the pandemic has impacted teaching with cultural heritage materials, certain findings and recommendations necessarily draw on issues that were present prior to the pandemic, but that the pandemic has exacerbated. These include topics such as discovery of digital cultural heritage materials, experiences teaching with learning management systems, and hybridizing course design, among others.

Instructors remarked frequently on the challenging and impressive work of their colleagues in campus libraries and museums during the pandemic. They also occasionally proposed suggestions to improve the ways in which library and museum staff support instructors when teaching in remote learning environments. Given that we did not interview staff working in galleries, libraries, archives, or museums, findings are necessarily skewed towards the needs of instructors and may reflect a disconnect in their understanding of library and museum strategy and operations. However, it is these instances of disconnect that are especially important to surface if these institutions are to collaborate with instructors more effectively in the future.

\section{Findings}

In most cases, the instructors we spoke with taught with collections on campus prior to the pandemic, coordinating with the library and/or museum to do so. These instructors drew from their own research practices and familiarity with archives, special collections, and museum collections, and brought awareness of these institutional holdings to their students through assignments that integrated cultural heritage materials into the curriculum. The challenges of accessing archival materials even in the best of times has been well documented: students and faculty regularly face challenges, which can vary from setting appointments with archivists, to acquiring written consent from an estate before access is granted. ${ }^{11}$ In 2021 , Ithaka $\mathrm{S}+\mathrm{R}$ published a report highlighting the common challenges instructors face in teaching with primary sources across a variety of academic fields as well as their perceptions of key issues facing them and their students. ${ }^{12}$

In many cases, adaptations during the pandemic were made with a desire to maintain some element of cultural heritage pedagogy, while accepting the impossibility of in-person

\footnotetext{
${ }^{11}$ Nicole Ferraiolo et al, "Terra Cognita: Graduate Students in the Archives, A Retrospective on the CLIR Mellon Fellowships for Dissertation Research in Original Sources," Council on Library and Information Resources, May 2016, https://www.clir.org/pubs/reports/pub170/.

${ }^{12}$ Kurtis Tanaka et al, "Teaching with Primary Sources: Looking at the Support Needs of Instructors," Ithaka S+R, 23 March 2021 , https://doi.org/10.18665/sr.314912.
} 
engagement with these materials. ${ }^{13}$ Although some instructors completely dropped the cultural heritage component of their classes, many felt it was important to continue engaging with cultural heritage materials because of the power of these materials to generate research questions, advance scholarship primarily across humanities and social science disciplines, and to excite and motivate their students toward further scholarly engagement and exploration.

\section{Hybridizing the Encounter with Cultural Heritage Materials}

A number of interviewees reported a tension-existing prior to but highlighted by the pandemic-between drawing on the expansive digital collections available online and losing the experience of sharing physical encounters with cultural heritage materials for their students. A few key findings emerged from these discussions. Some report a "flattening" of experience when digitally engaging with cultural heritage materials. This results from reducing one's sensory exposure to sight only, eliminating other forms of sensory engagement like touch and smell. As one instructor put it:

It's the physicality that's lost, you know? It's everything that goes with that in-person encounter. So, if you think of like sight is but one of the five senses, I think you get a sense of the other ways to engage with an object, including your other senses if you have the ability to be in-person with that object. You not only get this experience with an object itself, possibly the ability to handle it, but you also get to understand that object within the context of other objects, other collections, and it's that context, too, that's frequently lost.

The value of in-person engagement with collections is clear to instructors, but access to these collections is unevenly distributed, regardless of the way the pandemic has impacted access. A field of research has emerged to address this issue, exploring the potential of augmented reality and virtual reality to help with replicating the sensory experience of interacting with primary source materials virtually. ${ }^{14}$ Such technologies have the potential to not only expand access but add important context in the experience of engaging with digital cultural heritage materials.

As instructors have increasingly turned to digital cultural heritage materials during the pandemic, many have shared that they intend to continue to do so, incorporating them into hybrid course designs for future classes. Hybrid use of cultural heritage in this context involves utilizing digital cultural heritage materials in order to generate context that helps to deepen student interactions with a physical cultural heritage material. A number of instructors recognized this benefit to hybridized instruction, acknowledging that "that's where the new

\footnotetext{
${ }^{13}$ For another resource on adapting primary source pedagogy during COVID, see Amanda Boczar and Sydney Jordan, "Continuity During COVID: Critical Digital Pedagogy and Special Collections Virtual Instruction," IFLA Journal, July 2021, https://doi.org/10.1177/03400352211023795.

${ }^{14}$ Daniella Kalinda, Lucas Hrynyshyn, Gabby Resch, Anitha Nathan, Ravit David, and Ali Mazalek, "Tangible Augmented Reality for Archival Research: Using Augmented Reality to Research Cultural Heritage Items," MW20: MW 2020, 15 January 2020, https://mw20.museweb.net/paper/tangible-augmented-reality-for-archival-research-using-augmented-reality-to-research-culturalheritage-items/; Brady D. Lund \& Daniel A. Agbaji , "Augmented Reality for Browsing Physical Collections in Academic Libraries," Public Services Quarterly 14, no. 3 (2018) 275-282, https://doi.org/10.1080/15228959.2018.1487812.
} 
generation is," and expressing a need to "chase" that type of engagement in order to keep pace with their students. These observations speak to a tension, potentially productive, that exists between students and the instructors tasked with teaching information literacy. Instructors look to find the right balance of leveraging students' existing habits towards learning outcomes, as well as introducing new techniques of discovery for cultural heritage materials that are rooted in scholarly processes.

Many instructors valued engaging regional collections made available by public cultural heritage institutions. In some cases, instructors had used a hybrid engagement strategy with local museums and special collections before the pandemic, finding it useful to digitally peruse a collection before visiting it in person: "The Met functions in this way, where there is a robust apparatus online, particularly the Heilbrunn timeline because it links art pieces and essays and a literal chronological timeline they can look at. Then we can go to the Met together and look at particular galleries together."15 Instructors see great value in this model of dual-engagement with digital and physical collections: "It's really that combination of having a digital portion and an in-person piece, that are both reasonably easily accessible and also speak to each other, so the digital collection clearly reflects what exists in-person."

This hybrid model is likely to be more frequently employed as instructors and students regain access to physical collections. When a physical collection anchors a digital experience, it is easier for instructors to utilize the digital materials productively - the digital material serves as a launchpad for initial questions or as preparatory material for the in-person encounter. This observation echoes findings from a recent study analyzing the degree to which digitized cultural heritage materials across 42 digitized archival collections include "sufficient metadata to enable the viewer to understand that the virtual object is a representation of a physical object, that the physical object may be accessed, and that the physical object is part of a larger collection." The study finds a high level of variation, but frequently the connections between virtual images and physical materials are weak. ${ }^{16}$ Instructors regularly acknowledged and embraced the idea of a future in which digital cultural heritage materials were more thoroughly integrated into their course design, but in many cases, they resisted the idea that digital materials could replace the experience of engaging in person. Rather, digital materials are seen as a way to augment physical encounters with cultural heritage materials, expanding access and exposure to the breadth of materials available, and improving the chances that instructors can incorporate specialized materials for their students, regardless of limitations of physical access.

Recommendation: As instructors increasingly rely on hybrid course design, collections staff should continue to invest in collaborative pedagogical approaches to teaching with physical and digital cultural heritage materials, in order to facilitate asynchronous components of courses, while adding context to synchronous, physical encounters with cultural heritage materials.

\footnotetext{
15 The Helibrunn Timeline of Art History can be found on the Met Museum's website: https://www.metmuseum.org/toah/.

${ }^{16}$ Donald C. Force and Randy Smith, "Context Lost: Digital Surrogates, Their Physical Counterparts, and the Metadata that Is Keeping Them Apart," The American Archivist 84, no. 1 (2021): 91-118.
} 


\section{Adapting Curriculum}

While some instructors worked closely with archivists and curators and sought digital collections in order to try to refashion their preexisting curriculum as closely as possible, others decided that they would need to alter their courses and assignments more fundamentally and explored new approaches to teaching in remote environments.

Perhaps the most common of these examples was adding a guest lecturer, frequently relying on heritage professionals both from within and outside their institution. In one case, the museum had established a digital exhibition, and the instructor was able to record a conversation with the curator to supplement student engagement with the digital exhibition. In another case, the instructor shifted the focus of the class toward the emerging art market for non-fungible tokens (NFTs), bringing in a guest lecturer who had experience in this area. It was common for archivists to be invited to join a virtual class and discuss the principles and practices of archival research. There were also examples of instructors inviting artists and fellow scholars to give guest lectures.

Guest presentations appeared to be a popular adaptation, with several merits. In a fully remote environment, it was possible to secure participation from lecturers regardless of geography, opening up the range of potential speakers. Through this process, instructors were able to bring more and different kinds of primary source expertise into the classroom in ways that are less practical in person. Students were able to see primary sources through different lenses, not just via professor/researcher/archivist, but also through the eyes of curators, conservators, artists, or other heritage professionals, expanding the number of perspectives typically available in a fully in person classroom. Guest lectureship proved also a relatively tech-lite approach, making adjustments to the curriculum simple.

Another common strategy for adapting curriculum was shifting assignments from studying archival materials towards producing original material. Many adapted assignments included asking students to generate oral histories of the pandemic, a well-documented effective practice in undergraduate pedagogy. ${ }^{17}$ In some cases these assignments required having students interview their families and friends. In other cases, they were asked to keep a "Covid Journal" to record their experiences and reflections during the pandemic. As one instructor described,

I think that their stories are going to be super valuable to future researchers, and to professors who want to design courses. The idea is that future researchers might say, let's go back and see what people were documenting about themselves during the pandemic. It was very challenging in their final meditations for the class. With the exception of one person in the class it was totally personal, they connected all the readings to what they've been going through.

\footnotetext{
${ }^{17}$ Frances Davey, Kris De Welde, and Nicola Foote, "Oral History as Inspiring Pedagogy for Undergraduate Education," Oral History Education (2016): 110.
} 
As an important note for this particular exercise, the instructor included these materials in a time capsule archive that they were building in coordination with the library for researchers in 2030.

Instructors who adapted their assignments in this way found their projects to be effective in illustrating the ways in which cultural heritage is produced and that the work revealed a unique perspective from a moment in history. Instructors felt this context would help their students to more effectively engage with cultural heritage materials in the future, as the process of generating oral histories, written reflections, and correspondences can give them a greater sense of familiarity with how the archival record is created, what an archive might contain, and how to approach navigating an archive. Despite such exercises being a common mode of adaptation during the pandemic, for the most part, it remains unclear whether the outputs from these assignments will be integrated into the institution's collections in any way, or whether instructors will pursue a strategy to preserve the content.

Recommendation: The limitations in access to cultural materials necessitated by the pandemic caused a broad shift from studying cultural materials to creating them. Given the significance of the pandemic in world history, collecting institutions should consider how such materials might be collected and preserved. ${ }^{18}$

\section{Digitizing Institutional Collections}

Many of the instructors interviewed for this project were teaching longstanding courses in which at least a component of the course was centered around a locally held collection. Frequently the collections used in these courses were not yet digitized, and one of the most common approaches to adapting curriculum during the pandemic was to coordinate with archivists, curators, or other staff to digitize materials that were relevant to these courses. We saw a similar reliance on the knowledge of archivists and library staff in our earlier research on teaching with primary sources. ${ }^{19}$ However, during the pandemic instructors relied on more than these staff members' knowledge of institutional collections. They relied on their commitment to service. In order to digitize materials, staff had to be physically present in the library or museum, a sacrifice which instructors frequently applauded: "Yeah, I will say that our librarians have done a brilliant job and have really gone out of their way to make things as accessible as possible." He described how library staff went above and beyond during the pandemic to maintain a degree of access to collections:

The fact that they were willing to scan and digitize materials for this class is just amazing to me, because they've cut back their staff, they've cut back their hours, they've even cut back the number of journals they can support. It's just been this ongoing series of cuts. And by the way, Librarians did make arrangements for students to come in if they

\footnotetext{
${ }^{18}$ For an example, see Brooklyn College's COVID-19 archive: https://covid-19archive.org/s/brooklyncollege/page/collection-browse.

${ }^{19}$ Kurtis Tanaka et al, "Teaching with Primary Sources: Looking at the Support Needs of Instructors," Ithaka S+R, 23 March 2021 , https://doi.org/10.18665/sr.314912.
} 
absolutely had to, you know, on an individual, one-on-one basis, which I think is amazing because they're putting their own lives at risk. ${ }^{20}$

The increase of digitizing during the pandemic created an opportunity for instructors to identify materials that were appropriately representative of a collection, reflecting the value of their selections as high-usage archival materials. However, there was concern among instructors that these materials were not being systematically integrated back into the institution's digital holdings or tagged with metadata to allow for easy rediscovery and reuse. In one case, an instructor described having materials digitized but not being able to locate them in the collection afterward: "I also used sources from the library in a class to talk about the history of blackface minstrelsy, and blackface performance at our university, which they had done a survey of. But there were things that they provided to me that, then when I went back to look at it, I was like, 'Wait, I can't find this again."' While it is possible that in this example the instructor's failure to rediscover the digitized material was a function of their own lack of knowledge of the library's systems, it is critical that the library be made aware of such instances and speaks to a need for better standards for rediscovering materials that have been identified and digitized for courses, particularly if materials have been integrated into student assignments.

As instructors develop their curriculum and explore materials that the archives and special collections hold in relation to their coursework, it is likely that materials used once in a course may be used again or may be sought again by a student who later develops further research from an in-course assignment. This means that materials that are requested for digitization have a special value within the collection and tracking this usage can be helpful for current and future research and teaching. During the pandemic, instructors have made more digitization requests, making it an important moment for libraries to consider how material requests, generally, should fit into their digitization strategies, if they do not already do so.

Recommendation: Digitization efforts should track materials that were requested for digitization during the pandemic, especially for course use, if they do not do so already, by recording the appropriate metadata. When digitizing materials, there is value in tracking instructors' requests as evidence to make these materials more discoverable, and to inform future choices about which materials should be digitized.

\section{Determining Materials for Digitization}

Some instructors called for greater transparency into the digitization strategies of libraries, archives, and museums. As one instructor noted, it would be helpful to get a sense of how special collections librarians are thinking strategically about digitization:

Not that I want to dictate that or anything, but we're often planning out what we're going to be teaching, especially courses that are going to require students to have a more in-

\footnotetext{
${ }^{20}$ In acknowledging the risks museum and library staff made in working on-site during the pandemic, it is important to add that this was not always voluntary. On-site responsibilities did not fall evenly across employees and may have been traumatic for some or may have led to burnout.
} 
depth use of archival materials, multiple semesters in advance. I think it might be helpful to at least have that as sort of an input as they're thinking about what portions of collections they might want to look at digitizing and how to prioritize those things based upon what we think we'll be using within the next few semesters.

Such considerations are, of course, a critical component of existing digitization strategies already, but this disconnect between this instructor and the library suggests that more needs to be done to strengthen communication between these roles in the process of developing and executing digitization strategy. Because the increased need for digital materials during the pandemic made the process of digitization more visible to instructors, this is an ideal time for collecting institutions to increase instructors' awareness of their role in shaping their institution's strategy.

It was clear from the interviews that institutional archives see high use. Specifically, there is a growing interest from instructors and their students to use these sources to interrogate their own institutions. In the wake of George Floyd's murder and the racial justice movements responding to police brutality, many of the interviewed instructors brought an element of institutional critique to their curriculum by digging through institutional archives with their students. One instructor described his earlier efforts to use institutional archives to compare current and historic protests on campus. His library had an archive which documented the social justice protests on campus in 1970 - protests which were effective in bringing forth measurable demographic change in the university. In 2014, students who were protesting systemic racism on campus wanted to access that archive, but found there were too many barriers:

For students, particularly in the 21st century, so much information is readily accessible. But for them to have to go up to the library, which is not in the central part of campus, and to go through the processes to access the material, it felt restrictive to them. And it felt like it was so explicit to keep that important material and the history that it tells, hidden away. So one of the demands of the student movement was to have that collection be digitized. And the university felt that pressure and made it happen. So in my teaching that's an important part of students' understanding of how this collection is now available to us digitally.

This instructor has continued to teach with this particular collection, illustrating one unorthodox way of generating agency around digitization strategy. The act of and reason for digitization is an important part of a collection's history, a point which libraries, archives, and museums already recognize, but which instructors and students are becoming increasingly aware. During the pandemic, many new materials have been digitized to support remote learning and instructors, and students in the future may be able to glean valuable scholarly and pedagogical insights from this context. Because of this, it is important that collecting institutions act now to consider how the pandemic, and the actions taken in response to it, are being captured in metadata and institutional memory. 
Recommendation: Libraries, archives, museums, and special collections should capitalize on growing instructor and student interest in digitization to strengthen communication and grow awareness of their roles as stakeholders regarding digitization strategy and access policies. A part of this shared responsibility in determining digitization strategy must also involve finding ways to capture these strategic decisions in metadata and institutional memory as they become important points in an object's history.

\section{Licensing Non-Western Collections}

The shift to greater reliance on digital resources also revealed imbalances in institutional subscriptions. Some instructors suggested that greater investments in subscriptions for nonwestern digital collections, as well as improvements to the platforms that currently support these collections, and an expansion of the creation of new non-western collections, would be beneficial to the interests of students and their research. ${ }^{21}$ As one instructor noted, "In area studies, such as African studies and Middle Eastern studies, there's so little when it comes to digital archives, and so little of high quality. And I think that that is the major obstacle for our students. Our students naturally are interested in the wider world and the world beyond the United States and Europe." This instructor found that in some cases, access to digital collections had a scoping effect on what he was able to teach:

I hope to see that change soon or eventually, but that's the biggest problem I see. It's exacerbated [during the pandemic] because the digital collections are all they have, right? They can't use anything else. They can't go to the library anymore. So if you really are stuck with what's available online, inequity and inadequacy follows.

This set of problems was of course one that existed well before the pandemic. But even if the university did not have an abundance of non-western collections, instructors noted that they would often rely on public museums, libraries, and archives for in-person visits to non-western collections. However, during the pandemic remote learning has been reliant on institutional subscriptions to digital collections of cultural heritage materials.

As we found in the "Teaching Primary Sources" report, many students preferred accessing materials digitally prior to the pandemic. Because these students will also be tomorrow's researchers, the types of materials that are available digitally could have an impact on the direction in which a variety of disciplines grow. When those subscriptions trend towards investments in western cultural heritage at the expense of materials that are needed for nonwestern scholarship, it informs and delimits the possibilities for types and breadth of scholarship and learning. ${ }^{22}$

\footnotetext{
${ }^{21}$ In the context of the interviews, the term "non-western collection" was used in reference to collections that would be relevant to area studies disciplines representing the global south, Africa, Asia, and the Middle East.

${ }^{22}$ Lara Putnam, "The Transnational and the Text-Searchable: Digitized Sources and the Shadows They Cast," The American Historical Review 121, no. 2 (April 1, 2016): 377-402, https://doi.org/10.1093/ahr/121.2.377.
} 
However, increasing the digital availability of non-western collections can prove challenging due to a number of structural factors. ${ }^{23}$ While it is common across the board for materials to be dispersed across libraries and museums, and it is often the case that the holding institutions do not have sufficient funds to invest in digitizing cultural heritage materials generally, this is especially true of non-western collections, which have received less institutional investment, according to instructors. ${ }^{24}$

Recommendation: Libraries are constantly evaluating their subscription strategies. As instructors and students come to rely increasingly on digital resources for teaching and learning, it will be critical for libraries to identify any weaknesses in their collections brought to light by the pandemic.

\section{Student Fluency with Collections and Cultural Spaces}

Many cultural heritage institutions have tacitly excluded certain populations, whether because their staff are unwelcoming, a lack of programmatic representation, or tone-deaf communications. ${ }^{25}$ Calls for improving community relations, diversity of staff and program, and cultivation of an inclusive climate are urgently needed in many major cultural institutions. At the same time, research has shown that cultural heritage institutions have the power to craft experiences for visitors which can improve their comfort and fluency navigating collections and conducting research. ${ }^{26}$ Academic museums and libraries are especially poised to generate these opportunities, as they often present students with regular access to cultural heritage spaces, as well as staff support.

Instructors found that one of the most challenging aspects of teaching with cultural heritage materials during the pandemic was the inability to provide their students with opportunities to gain comfort and confidence engaging with physical collections and navigating cultural spaces. This is particularly important for students who might feel excluded from cultural institutions based on implicit or explicit racism, classism, ableism, or gender and other forms of identity discrimination.

In many cases instructors were introduced to the importance of this aspect of teaching for the first time after losing the opportunity to bring their students into the library or museum. One

\footnotetext{
${ }^{23}$ Kimberly Christen, "Does Information Really Want to Be Free? Indigenous Knowledge Systems and the Question of Openness," International Journal of Communication 6 (2012), https://ijoc.org/index.php/ijoc/article/view/1618/828.

${ }^{24}$ Inna Kizhner, Melissa Terras, Maxim Rumyantsev, Valentina Khokhlova, Elisaveta Demeshkova, Ivan Rudov, Julia Afanasieva, "Digital Cultural Colonialism: Measuring Bias in Aggregated Digitized Content Held in Google Arts and Culture," Digital Scholarship in the Humanities 36, no. 3 (September 2021), https://doi.org/10.1093/llc/fqaa055.

${ }^{25}$ Some historical examples of explicit exclusion are referenced in Ithaka S+R's case study of the Studio Museum: Roger Schonfeld and Liam Sweeney, "An Engine for Diversity: Studio Museum in Harlem," Ithaka S+R, 23 January 2018,

https://doi.org/10.18665/sr.306190. Examples of more current instances of exclusion and poor communication can be found here: Nancy Kenney, "After 2019 Racial Incident, MFA, Boston Hires a Senior Director of Belonging and Inclusion," The Art Newspaper, 4 September 2020, https://www.theartnewspaper.com/2020/09/04/after-2019-racial-incident-mfa-boston-hires-a-senior-director-ofbelonging-and-inclusion; Nancy Kenney, "Indianapolis Museum Apologises for Posted Job Description Describing a 'Core, White Art Audience,'” The Art Newspaper, 15 February 2021, https://www.theartnewspaper.com/2021/02/15/indianapolis-museum-apologisesfor-posted-job-description-describing-a-core-white-art-audience.

${ }^{26}$ Liam Sweeney, "Small but Mighty: Spelman College Museum," Ithaka S+R, 7 June 2018, https://doi.org/10.18665/sr.307535.
} 
instructor spoke at length to this capacity for the encounter to activate students' sense of ownership of their own knowledge:

My belief is that when I am teaching students, special collections is one of the first things we do. That's because they have a very hard time seeing themselves as scholars. There's a lot of imposter syndrome. And seeing themselves as worthy of producing knowledge themselves from their positionality is so important. Actually holding these things, I don't know how to describe it, there's a magic that happens; they start to feel like they are real scholars, like, I was trusted with this old thing. I can look at this object, which doesn't tell me what to think of it, and then I can present it to the rest of my cohort and say what I think of it. And that day to me is transformative.

I remember this one student who held all the papers of the KKK that were local to where our campus is, and watching her go from having tons of imposter syndrome in the morning to the fact that she got to make pronouncements about these people who had been horrible to her family members, it was this transformative moment for her thinking 'I can do this and also there's power in me doing it and I want to do it.'

Part of the power in that act is having someone trust you with this historical object that you could destroy, really, and like seeing it in front of you, realizing it's real and that I get to say something about it. And so I always try to do that super early in the process because I think it starts to change them. We can't do that the same way. It's just not the same on Zoom with a bunch of faces looking at a digital document. There's aspects of it we can't get.

This instructor observed that the act of handling and studying of historical materials empowered students to newly imagine their work as participating in a larger community and scholarly conversation. Losing time in these spaces due to the pandemic has caused students to miss opportunities to have such experiences with archival materials.

Another instructor pointed out that missing out on such moments of potential discovery and self-empowerment is less of a pressing issue for seasoned researchers who have already had meaningful experiences in the archive: "I mean I think if you're an experienced researcher you've had your good time. So the digitized stuff helps you do your research, and there are obvious advantages too to not having to spend the money to travel." While many instructors speak with great energy about the power of physical encounters with the object for their students, there came a point when the convenience of digital materials superseded the value of a physical encounter with an object, especially as the researcher must gain a more comprehensive understanding of their subject.

Several instructors grappled with describing these learning outcomes, precisely because they are more about intangible experiences that shift a student's relationship to learning. However, some instructors reported that in evaluations they often read testimonies from students sharing that their engagement with archives was their favorite part of the class. 
Recommendation: As students were shut out from collections spaces over the course of the pandemic, important opportunities to acclimate students to these spaces have been lost. Instructors and collections staff should prioritize reengaging students in these spaces, particularly those who may not feel comfortable in cultural institutions, to develop familiarity and competency navigating physical collections, in order to prepare students to confidently engage cultural heritage spaces outside of an academic context. Platforms that host digital cultural heritage materials should seek to replicate the experiential elements of in person engagement, perhaps through augmented reality tools or interactive and/or social components to digital encounters with cultural heritage material.

\section{Discovery and Commercial Search Engines}

When there is no option for in person engagement, students' online strategies become especially important, and weaknesses in their discovery methods become more pronounced. The most common first-and in many cases the last-step towards identifying relevant primary sources among undergraduates is typically via Google. Instructors were almost entirely aligned in recognizing that the sophisticated user experience of the Google search engine has crafted their students' processes of conducting research, including seeking primary sources. Instructors reported that it takes significant effort to train their students to employ different research methods and tools. ${ }^{27}$ However, on most campuses, this kind of digital research training does not appear to be explicitly managed by any particular or designated instructor, librarian, curator, or any other administrator. In some cases, instructors described digital literacy efforts by librarians to share best practices when seeking primary source content. More frequently, instructors addressed these issues on a case-by-case basis, using their own subject area expertise to illustrate alternatives or supplements to Google. As one instructor described: "I get a lot of cases where students have Googled and ended up using sources that aren't credible. And that is like a huge drawback. First of all, it slows them down. But also, when they Google for journal articles, they're not being led through the process of where to search and how to search for primary source content." 28 In another case, an instructor explained that students might use Google Scholar to conduct their research, but because they had not logged in to the library portal, they were only reading the abstracts of journal articles.

Interviews revealed shortcomings of using both the traditional platforms through which scholarly communications are hosted and accessed and Google for primary source discovery. ${ }^{29}$ The problem of where to begin the research process continues to confound the smooth adoption of digital discovery of primary source content, particularly among undergraduates. Even as Google and other search engines provide an easier access point to some type of content, they typically do not situate that content within a broader context, or in create a sense of serendipity

\footnotetext{
${ }^{27}$ For evidence that despite Google's ubiquity, students struggle with discovery, see: Kathleen Fear, "User Understanding of Metadata in Digital Image Collections: Or, What Exactly Do You Mean by 'Coverage'?" The American Archivist 73, no. 1 (2010): 2660.

${ }^{28}$ It is unrealistic to expect that students will abandon Google in favor of less user-friendly starting points to discovery. Instead, instructors and librarians should help students understand the appropriate role Google can play within a suite of discovery tools.

${ }^{29}$ Safiya Umoja Noble, Algorithms of Oppression, New York University Press, 2018.
} 
in the process of discovery. For instance, one instructor explained that usage of archival content is an important metric for him while conducting research:

As a historian when I go into an archive, or if I have a conversation with an archivist, I'll often ask them what's currently being processed, or what are some intriguing pieces of your primary material that people haven't looked at or don't look at very much. I'd like to figure out a way to give the students a sense of what's been utilized frequently in the archive and what hasn't.

While archivists retain this knowledge through familiarity with their collections, digital platforms are often able to track usage statistics for materials in their collections. This may be provided to librarians to indicate the value of the content, but it is not typically made available to end-users to inform their navigation of the material.

What are the relevant metrics and connecting threads that could help digital platforms to replicate some of the more appealing elements of engaging with collections in person? This same instructor shared that he still tells his students, "Go to the stacks. Look for a book, and see what books are around the one you are looking for." Most instructors emphasized the value of accidentally finding relevant materials during the process of research. "The thing that I think is difficult to replicate, is unintentionally finding the exact book you didn't know you needed." While this instructor was referring to the process of browsing monographs, the same principle can apply to discovery of physical primary sources, where the discovery process often involves situating the context of a material in relation to the larger collection.

The common practice of developing pathfinders, LibGuides and/or research guides can yield value in navigating complex digital scholarly communication platforms. However, it was not common that instructors utilized such resources when teaching with digital cultural heritage materials. In one case, an instructor described a useful research guide that their librarian had developed for accessing digitized and born-digital materials on the topic of Germany and the Holocaust. $3^{\circ}$ This tool centralizes databases that have relevant content and then lists suggested search terms that can be used to yield strong search results. If scholarly platforms worked together to scale such a framework with the intention of blending ease of access with serendipitous discovery, students would benefit from engaging in a scholarly communications ecosystem with a low bar to entry and an engaging set of tools to facilitate discovery. ${ }^{31}$

These findings raise a question for further exploration, which is beyond the scope of this study: how might digital cultural heritage platforms more seamlessly and systematically cooperate to collectively improve user experiences?

Recommendation: Platforms that host primary source collections should consider designing for user experiences that more effectively contextualize discovery processes to replicate the serendipity of physical research with collections. For instance, digital collections platforms

\footnotetext{
${ }^{30}$ An example of this research guide can be found here: https://libguides.utsa.edu/germany and holocaust

${ }^{31}$ Google Scholar's "cited by" and "related articles" are useful tools in this regard.
} 
should be engineered to allow display of archival materials in their original order, according to folder.

\section{Frustrations with Platforms}

Instructors reported that college and university administrations made big investments in expanding their learning management systems (LMS) and training for instructors in how to use these tools during the pandemic. LMSs can be valuable tools for helping instructors teach with digital cultural heritage materials in remote learning environments. They can be used as locations for sharing selected materials and simulating class discussion. They can also prove challenging to instructors for a number of different reasons. One instructor described that despite making investments in this technology and promoting training, the demands of working with their university's LMS caused an additional burden during the pandemic:

It was common that the video wouldn't come up, or students couldn't access the content. So, it was exhausting in that you just had to really do a lot of planning, you always needed a plan B. And I think that's why some faculty-you know, it burned out faculty really quickly. I know I was experiencing burnout by the end of winter. It was really overload. And I imagine for students it was, too."

One instructor explained in great detail his frustration with the LMS. In his view, working with this software was the most challenging part of adapting to remote learning. While the university promised that the LMS would allow for a smooth transition into a remote learning environment, problems arose when the system produced glitchy results for users. While the institution paid for elaborate plug-ins and extensive training for faculty, students were unable to effectively access the platform without high-speed internet, this instructor reported:

We've been finding that when everyone in class has to use it, you start to see that certain people who don't have high speed internet, they don't have access to the necessary technology. People are constantly having problems with their browser. Last semester students were constantly getting bumped out of [the LMS]. Different features didn't appear to be working the way they were supposed to. And then we get emails from the administration saying [the LMS] is down for maintenance. Now we're so dependent upon it, and its problems are even worse. It's just a big monopoly and they don't have a good product and we're all stuck with it. And now we're depending on it. And it's part of the problem in my view.

Instructors also described struggling with teaching students how to use platforms for scholarly content with interfaces that were difficult to navigate or simply failed to deliver results for students. As one instructor explained, they were not asking their students to conduct advanced searching or Boolean based searches, but simple searches where the platforms simply did not perform. Many universities had poor digital infrastructure for teaching and learning going into the pandemic, and this created a burden on instructors and students alike to utilize inadequate infrastructure as the primary structure for courses. 
When the technology needed to conduct this work is dysfunctional, it creates major frustrations in an already tense setting. Such technical failures can make the difference between effectively adapting to a remote learning environment or withdrawing from actively engaging in a course due to feelings of futility and stress.

Recommendation: Learning Management Systems are not optimized for all types of instruction, but the pandemic has made it clear that such support will be essential in the future. Platforms should expand the functionality of teaching and learning infrastructure and enable students to access and utilize digitized cultural resources. Universities should demand more of their vendors based on the large amounts that they charge for mediocre experiences.

Additionally, libraries that have created clear instruction guides for the specific digital platforms they license may need to consider additional outreach to make instructors aware of these guides.

\section{Conclusion}

The pandemic has transformed higher education in many ways, but it has produced a particular set of challenges for those who required physical access to cultural heritage materials to teach their classes. These instructors have relied on several strategies to adapt their curriculum during the pandemic. They relied on colleagues such as library and museum staff, archivists, and curators to be present on campus to digitize and grant access to their collections. They incorporated open access digital collections into their curriculum. They have learned about their own limitations and have sought opportunities to improve their ability to teach with digital cultural heritage materials. They adapted their assignments to include lectures from heritage professionals, and, in some cases, they changed assignments to invite students to produce materials that reflected their own stories during the pandemic.

Digital tools and virtual engagement techniques have created opportunities to share cultural heritage materials across different locations and communities, expanding the reach of archives and collections that were previously available only to a select few-most regularly students, faculty, and staff of well-resourced institutions. While digitized collections and virtual engagement services have grown more robust as a necessity of remote learning, our interviews revealed that the pandemic has been disproportionately challenging for their most vulnerable students, often students of color. Institutions must consider how to apply the values of equity and inclusion to their remote teaching protocols and technologies to prevent minoritized student populations from facing unfair and unnecessary challenges while attending school remotely. In order for instructors to effectively teach with cultural heritage materials, remote learning technologies must prove to be highly functional and available for all their students.

Instructors fear that the pandemic has prevented students from gaining important experiences within cultural institutions, experiences that can give them access to resources that legitimize their scholarly work and provide familiarity with exploring archives, special collections, and museum galleries. There remains a need for increased digitization of library collections to allow for remote access, even as colleges and universities have returned to in-person learning. 
Instructors have found great value in using digital collections during the pandemic and find it likely that digital collections will have an increased presence in their curriculum moving forward. This presents opportunities to expand access to cultural heritage materials in a more equitable way for students, regardless of which institution they attend. It is important for universities to make investments in staff and infrastructure to create and support digital collections, with a focus both on the user experience of such digital tools, as well as the types of content that are being digitized, in order to ensure a breadth of cultural narratives are available for study in digital contexts. 